\title{
SOCIEDADES ADULTOCÉNTRICAS: SOBRE SUS ORÍGENES Y REPRODUCCIÓN
}

\author{
Claudio DUARTE QUAPPER* \\ A la familia Martí Escofet \\ por su cariño
}

\begin{abstract}
RESUMEN
Nuestra sociedad occidental puede ser caracterizada conceptualmente desde diversas nociones según los ejes de observación que se privilegien en el análisis. Para el caso de este ejercicio reflexivo, el eje principal es el de las relaciones entre clases de edad, específicamente juventud y adultez. Desde esa perspectiva, decimos que se trata de una sociedad adultocéntrica, producida como resultado de diversos procesos económicos y políticos que han consolidado materialmente este modo de organización societal, así como de la construcción de su matriz sociocultural que —en un plano simbólico-, potencia su recreación y reproducción, construyendo imaginarios que afectan directamente las relaciones y los procesos identitarios de diversos sujetos sociales. La presente reflexión muestra procesos que han posibilitado la emergencia y reproducción de sociedades adultocéntricas, leído desde las condiciones y situaciones de las y los jóvenes.
\end{abstract}

\footnotetext{
PALABRAS CLAVE: LO JUVENIL, JUVENTUDES, SER JOVEN, PRODUCCIÓN SOCIAL, NATURALIZACIÓN, SOCIEDAD ADULTOCÉNTRICA, IMAGINARIOS ADULTOCÉNTRICOS
}

* Sociólogo y Educador Popular. Magíster en Juventud y Sociedad, Universidad de Girona. Doctorando en Sociología, Universidad Autónoma de Barcelona. Académico del Departamento de Sociología de la Universidad de Chile, coordinador del Núcleo de Investigaciones en Juventudes. E-Mail: claudioduarte@u.uchile.cl. 


\title{
SOCIEDADES ADULTOCÊNTRICAS: SOBRE SUAS ORIGENS E REPRODUÇÃO
}

\begin{abstract}
RESUMO
Nossa sociedade ocidental pode ser caracterizada conceitualmente a partir de diversas noções segundo os eixos de observação privilegiados na análise. Para o caso deste exercício reflexivo, o eixo principal é o das relações entre as faixas etárias, especificamente juventude e adultez. A partir desta perspectiva, dizemos que se trata de uma sociedade adultocêntrica, produzida como resultado de diversos processos econômicos e políticos que consolidaram materialmente este modo de organização social, assim como da construção de sua matriz sociocultural que —em um plano simbólico-, potencializa sua recriação e reprodução, construindo imaginários que afetam diretamente as relações e os processos identitários de diversos sujeitos sociais. A presente reflexão mostra processos que possibilitaram a emergência e reprodução de sociedades adultocêntricas, a partir das condições e situações dos e das jovens.
\end{abstract}

\section{PALAVRAS CHAVE: JUVENIL, JUVENTUDES, SER JOVEM, PRODUÇÃO SOCIAL, NATURALIZAÇÃO, SOCIEDADE ADULTOCÊNTRICA, IMAGINÁRIOS}

ADULTOCÊNTRICOS

\section{ADULTCENTRISM SOCIETY: FOCUSING ON ITS ORIGIN AND REPRODUCTION}

\begin{abstract}
Our Western society can be characterized conceptually from different notions according to the axes of observation in the analysis privilege. In the case of this reflective exercise, the main focus is the relationship between age classes, specifically youth and adulthood. From that perspective, we say that this is an adult-centered society, produced as a result of various economic and political processes that have materially strengthened this mode of societal organization and construction of sociocultural matrix, on a symbolic level, power recreation and play, imaginary building that directly affect relationships and identity processes of different social subjects. This reflection shows processes that have enabled the emergence and reproduction of an adultcentered society, read from the conditions and situations of young people.
\end{abstract}

KEY WORDS: YOUTH, JUVENTUDES, BEING YOUNG, SOCIAL PRODUCTION, NATURALIZATION, ADULTCENTRISM SOCIETY, ADULTCENTRISM IMAGINARIES 


\section{INTRODUCCIÓN}

UNO DE LOS ASPECTOS ampliamente debatidos en los estudios sobre juventudes alude al carácter de producción social que ella posee. De esta forma, se ha enfrentado una noción paradigmática anterior que planteaba una condición psicobiológica como característica definitoria del ser joven, otorgándole a los caracteres propios del crecimiento biológico y psicológico la capacidad de definir y clausurar la constitución de ciertos individuos en personas jóvenes. Sin embargo, el debate de los últimos treinta años en América Latina y en Chile ha abierto nuevas miradas, nuevos enfoques - que en diálogo con elaboraciones provenientes de Europa y Estados Unidos han desplegado con diversos grados de sistematicidad-, miradas que ponen de relieve otros factores al momento de conceptualizar el carácter de el ser joven-la persona joven, como énfasis en la condición de sujeto/a y/o actor que tendrían los individuos socialmente considerados jóvenes; la juventud, que en una acepción más múltiple puede referir a una etapa de la vida, grupo social, actitud ante la vida y que se enfatiza en su condición de diversidad y pluralidad -las juventudes - (Duarte, 2001); lo juvenillo joven, como las producciones que las y los jóvenes realizan, así como las que socialmente se elaboran respecto de ellos y ellas (Duarte, 2005); la juvenilización, como proceso social que produce e impone lo juvenil como una esencia que se autosustenta y que puede existir independiente del resto de la sociedad (Margulis, 1996). ${ }^{1}$

Un eje que cruza transversalmente estos cuatro modos de concebir refiere a que se trata de una producción social, en que las claves históricas, económicas, culturales, políticas y sociales - entre otras-, han de ser consideradas y explicitadas como elementos definidores en estos ejercicios de conceptualización. ${ }^{2}$ Ello ha generado cambios y

1 De los cuatro modos señalados, lo juvenil es a nuestro juicio la categoría más comprensiva, en tanto da cuenta de la condición relacional del ser joven y de las distintas formas de concebir-producir jóvenes, juventud (es) y juvenilización. Por ello, la nominación que utilizo es sociología de lo juvenil, para poner de relieve el propósito de hacer un análisis comprensivo de esta condición estructural y estructurante (Duarte, 2005). La misma opción asumo en este artículo.

2 Bourdieu (1990) abrió de manera potente este debate al señalar, con cierta ironía, que «la juventud no es más que una palabra», cuestionamiento que retomó, ahora desde la sociología, las posiciones diferenciadas en los enfoques que relevaban naturaleza o cultura, y que habían 
aperturas relevantes en los enfoques con los cuales se observan las juventudes y lo juvenil (Alpízar y Bernal, 2003; Duarte, 2005), los tipos de preguntas que orientan las investigaciones (Aguilera, 2009), los métodos de estudio (Pérez Islas, 2006), las nociones utilizadas (Dávila, 2004).

De esta forma lo juvenil y las juventudes han sido incorporados en el debate, como una producción diferenciada que exige considerar las posiciones — con diversidad y dinamismo - que las y los jóvenes tienen en la estructura social, las situaciones específicas que en tanto grupos sociales experimentan y al mismo tiempo, las condiciones en las cuales despliegan-inhiben sus vidas (Martín Criado, 1998).

Si consideramos lo juvenil desde este enfoque de construcción social, una delimitación conceptual que hemos de hacer refiere al carácter relacional que esa producción tiene. Vale decir, la construcción de lo juvenil ha de elaborarse a partir de las múltiples e infinitas relaciones que establecen los sujetos jóvenes de ambos sexos desde sus diversas posiciones sociales. Lo anterior apela a sus condiciones de jóvenes que se producen por semejanzas y diferenciaciones; o si se quiere, por asimilaciones y resistencias, continuidades y rupturas.

Esta producción de sociedad remite a unas ciertas relaciones sociales que se despliegan y que pueden ser leídas a través de diversos ejes - clase, género, etnicidad, entre otros-. Para nuestro interés, por ahora podemos enunciarlo como una lectura desde la noción conceptual de clases de edad, en tanto ella refiere «en un momento del tiempo, a la división que se opera, en el interior de un grupo, entre los sujetos, en función de una edad social: definida por una serie de derechos, privilegios, deberes, formas de actuar... - en suma, por una 'esencia social' - y delimitada por una serie de momentos de transición - que difieren históricamente: matrimonio, servicio militar, primera comunión, certificados de escolaridad...-. [...] Esta división de clases de edad, por tanto, es una variable histórica: no depende de una serie de 'naturalezas psicológicas' previas, sino que se construye en el

emergido sistemáticamente a principios del siglo XX desde quienes investigaron sobre juventudes en Estados Unidos y que marcaron tendencias: Stuart Hall en la primera posición (1984) y Margaret Mead en la segunda (1973). Posteriormente, estos enfoques contrapuestos no tuvieron la misma continuidad, asumiéndose como hegemónica la elaboración naturalizadora de lo juvenil y quedando como marginal la que buscaba relevar aspectos contextuales. En las últimas tres décadas esta situación ha cambiado en la región (Pérez Islas, 2006). 
seno de cada grupo social en función de sus condiciones materiales y sociales y, sobre todo, de sus condiciones y estrategias de reproducción social» (Martín Criado, 1998; 86).

Esta noción nos permite leer las sociedades occidentales ${ }^{3}$ como constituidas por la interrelación entre clases de edad que cotidianamente definen - desde sus diversas posiciones - los modos de relación que establecen, las decisiones que toman y el control que de ellas pueden tener (poder/autonomía), y los criterios desde los que sostienen sus prácticas, discursos e imaginarios (habitus). Dichas lecturas han de considerar los otros ejes constitutivos ya señalados y que se trata de ejercicios de objetivación de realidades dinámicas en continua transformación, en que las delimitaciones de fronteras entre grupos son resultados y factores de las luchas de poder por la reproducción entre los propios grupos (Martín Criado, 1998).

Podemos explicitar entonces que nos posicionamos desde la consideración del carácter de construcción social, ya no solo de lo juvenil, sino de las diversas clases de edad — niñez, adultez, adultez mayor-, para desde ahí reflexionar en torno a una característica que posee nuestra sociedad occidental y es su condición adultocéntrica. Ella remite a unas relaciones de dominio entre estas clases de edad $-\mathrm{y}$ lo que a cada una se le asigna como expectativa social—, que se han venido gestando a través de la historia, con raíces, mutaciones y actualizaciones económicas, culturales y políticas, y que se han instalado en los imaginarios sociales, incidiendo en su reproducción material y simbólica.

El presente texto surge como ejercicio reflexivo de sistematización, de un conjunto de conversaciones sostenidas en el marco de experiencias formativas en organizaciones sociales de diverso tipo y docencia universitaria en varios países de América Latina y el Caribe, y apoyado en una investigación bibliográfica. La motivación política del mismo radica en ofrecer una palabra fundada sobre una de las ideas que por años he venido trabajando y sometiendo a discusión: el carácter adultocéntrico de nuestra sociedad y de las relaciones que en ella desplegamos, para su comunicación y profundización. La motiva-

3 Franz Hinkelammert define la sociedad occidental como aquella formada durante la edad media y que se ha caracterizado por ser dominadora del mundo entero a través de la colonización, el racismo, el hambre, guerras, sistemas de dominación extremos, fuerzas productivas que se sostienen en la depredación, la ilusión de la libertad humana y como solución a los problemas que ella misma crea $(1991 ; 1998)$. 
ción práctica es cerrar parte de mis estudios de postgrado, por lo cual agradecer a docentes y estudiantes de la promoción 2010-2011 del Magíster Interuniversitario en Juventud y Sociedad, coordinado por la Universidad de Girona, Cataluña, por la rica experiencia vivida en este tiempo y por sus aportes, que con seguridad me han ayudado a crecer.

\section{ADULTOCENTRISMO COMO PROCESO HISTÓRICAMENTE PRODUCIDO}

Existen relatos sistemáticos de fases de la historia humana o de sociedades específicas en que se enfatiza en las relaciones que se producían entre clases de edad, a partir de evidenciar los procesos de emergencia de juventud y niñez (Feixa, 1998). Relevaremos el carácter conflictivo de estas relaciones en tanto constituyen asimetrías que contienen y reproducen autoritarismo (Gallardo, 2006).

En las sociedades primitivas sin Estado, la posible constitución de juventud estaba enmarcada - dentro de una amplia diversidad - por la existencia de ritos de pasos que señalaban el cambio de estatus de niños y niñas, para comenzar a jugar roles vinculados a la participación en las labores productivas, reproductivas y de defensa; lo que en algunos casos implicaba «el acceso a la vida adulta» o en otros «el ingreso en un grupo de edad semidependiente previo al matrimonio» (Feixa, 1998:20). Existían distintas ritualidades, por medio de las cuales se otorgaba legitimidad a la nueva condición de sus integrantes (Turnbull, 1984).

Nos interesa debatir el carácter de estos procesos, ya que los «sistemas de edades sirven a menudo para legitimar un desigual acceso a los recursos, a las tareas productivas, al mercado matrimonial, a los cargos políticos» (Feixa, 1998:25). De esta manera, una característica de estas relaciones sociales primitivas es que se legitimaba la jerarquización entre edades, y con ello se aseguraba la subordinación de los sujetos y sujetas construidos como menores. Estas jerarquizaciones productoras de asimetrías se originaron y sostienen hasta hoy, sobre las ya existentes de orden patriarcal, en que las mujeres perdieron las posibilidades de ejercicio de poder en sus sociedades y fueron relegadas a roles reproductivos y productivos domésticos, sin capacidad en el plano de las decisiones políticas, económicas y sexuales (Simone de Beauvoir, 1998).

Diversos autores plantean que el patriarcado es un sistema de dominación que contiene al adultocentrismo: «en términos estrictos, el monopolio patriarcal es ejercido por los varones designados socialmente como adultos. [...] Contiene [el patriarcado] la práctica de un 
adultocentrismo, por el cual la autoridad legítima y unilateral reposa 'naturalmente' en los adultos y también en las prácticas de discriminación de género con dominio patriarcal» (Gallardo, 2006; 230; Abaunza et al., 1994). Este patriarcado se habría gestado por necesidades que impuso la guerra, que generó ciertas ventajas a los varones (tamaño, fuerza y mayor velocidad); y por el sostén y transmisión generacional de la propiedad (herencia) mediante la atadura forzosa de la mujer.

En la Roma antigua - siglo II A. C. - los cambios en el sistema económico y social habrían sido detonadores de la emergencia de una juventud, por medio de legislaciones en que el Senado aprobó un conjunto de leyes que trasladan el reconocimiento de la adultez desde la pubertad hasta los veinticinco años. La Lex Plaetoria impedía la realización de negocios con personas menores de dicha edad y la Lex Villia Annalis limitaba a estos menores para la participación en cargos públicos: «La juventud o la adolescencia hacen pues su aparición histórica como una fase de subordinación, de marginación, de limitación de derechos y de recursos, como incapacidad de actuar como adultos, como fase de semidependencia entre la infancia y la edad adulta» (Lutte, 1992:22). Si bien las leyes que se dictan son presentadas como medidas que buscaban defender a las y los jóvenes, su efecto fue en el sentido inverso, ya que al fundar esta nueva clase de edad, lo que pretenden más bien es garantizar «una serie de transformaciones socioeconómicas cuyo resultado es concentrar la riqueza y el poder en las manos de unas minorías privilegiadas con la finalidad de obtener derecho» (Lutte, 1992:22-23). Estos grupos dominantes son los grupos de clase alta, masculinos y de mayor edad, que se erigen como controladores de campos económicos y políticos de la organización societal.

Esta dictación de leyes y construcción de juventud incidió en varones de los sectores privilegiados de dicha sociedad; el resto de hombres y mujeres tardaron bastante tiempo en ser reconocidos como personas y como jóvenes, mientras tanto estaban en situación de invisibilidad social lo que se agravó con las dominaciones ya existentes de clase y género. De esta manera, comienzan a asentarse las bases de un modo de relación en sociedad respecto de las y los sujetos considerados «menores», a quienes, a partir de su condición de edad se les remite a posiciones de subordinación.

En esta perspectiva, la niñez también es una construcción social que ha existido en diferentes momentos - emergiendo y desapareciendo - de la historia europea (Ariés, 1990; DeMause, 1982; Pollock, 1990; Stone, 1986). Esta dinámica ha sido influida por variacio- 
nes demográficas producto del aumento de la esperanza de vida; la valoración e importancia otorgada a los procesos educativos como acción diferenciadora de las responsabilidades de cada grupo de edad - los grupos adultos encargados de la formación de los sujetos considerados menores, y la tarea de estos, dejarse formar para lograr ser aceptados- - La familia europea de los siglos XVIII y XIX se constituye como el lugar principal para esta función social y espiritual, y más tarde la escuela será la encargada de la formación para la vida. Ariés (1990) insiste en que un indicador de este proceso es el paso del impudor a la inocencia, siendo esta última construida como debilidad. De ahí que la tarea de la educación sea enfrentarla a través de la enseñanza y la disciplina como mecanismo de fortalecimiento para el desarrollo del carácter y de la razón.

En la Edad Media, los niños vivían mezclados con los adultos y no había una definición clara de proceso educativo, se carecía de una ritualidad que marcara diferencias entre uno y otro estadio. En la época moderna al emerger la escuela, lo que se instituye es un rito de paso que establece una marca que diferencia - en cuanto roles y posición en lo social - a la niñez y posteriormente a la juventud respecto de la adultez. «La familia y la escuela retiraron al niño de la sociedad de los adultos. La escuela encerró a una infancia antaño libre en un régimen disciplinario cada vez más estricto, lo que condujo en los siglos XVIII y XIX a la reclusión total del internado. La solicitud de la familia, de la iglesia, de los moralistas y de los administradores privó al niño de la libertad de que gozaba entre los adultos. Esta solicitud le infligió el látigo, las correcciones reservadas a los condenados de ínfima condición» (Ariés, 1990:542). Vale decir, se instituye un modo de ser niño, niña y joven asociado a la experiencia de la obediencia y la sumisión en el contexto de dos instituciones vitales para este modo de sociedad: la escuela y la familia.

La escuela aporta a la sociedad, entre otros factores, la diferenciación etaria de estudiantes, la especificidad de roles entre jóvenes y adultos, la institucionalización de características que son impuestas como esencias de las clases de edad: profesores/as (adultos) mandan y los alumnos (niñas, niños y jóvenes) obedecen (Ariés, 1990).

La familia aporta, entre otros aspectos el carácter sobrerrepresivo de la misma y su estructuración en función de dicho propósito: autoridad unidimensional y arbitraria, vulneradora de posibilidades, negación de sujetos/as; todo lo anterior encubierto en cuestiones ideológicas como exclusividad sexual, amor, protección, abnegación y gratitud (Gallardo, 2006). 
Parte de la investigación histórica muestra que en el territorio que hoy es América Latina y el Caribe, antes de la invasión española y portuguesa, en la amplia diversidad de culturas que la habitaban, las relaciones entre grupos de edad se caracterizaban por dos aspectos: de una parte, en pueblos aztecas, la vinculación de individuos jóvenes a procesos específicos de preparación para la guerra y las labores religiosas, a través de tareas de ayuda a los adultos encargados en esos ámbitos, cuestión que les preparaba también para asumir posteriormente responsabilidades de formar familia y tener descendencia (Carrasco, 1979); y por otra parte, en la alta consideración de niños y niñas a quienes llamaban 'piedras preciosas', porque aseguraban la continuidad del grupo y las tradiciones (Rodríguez, 2007). ${ }^{4}$

En Chile, la emergencia del sujeto joven y del grupo social juventudes está dado por la confluencia de al menos dos procesos: uno, las paulatinas transformaciones en el modo de producción económico y político dominante con posterioridad a la guerra de independencia: el paso de las estructuras económicas coloniales - fundamentalmente agrícolas, ganaderas, comercial y de pequeña minería - hacia la gestación de estructuras capitalistas, sostenida en progresivos procesos de industrialización, lo que trajo transformaciones profundas en la organización familiar y del trabajo. El segundo proceso, resultado del anterior, estuvo dado por la ampliación y emergencia del sistema educacional en el país, como preparación para el mundo del trabajo, y de la necesidaddeber de participar de la formación escolar que comenzó a ser aceptada en nuestra sociedad (Goicovic, 2000; Salazar y Pinto, 2002).

A la institución escolar fueron integrándose diferenciadamente grupos, que anteriormente pasaban de niñez a adultez por el rito de paso del matrimonio, ${ }^{5}$ o la incorporación a las tareas productivas de las nacientes Repúblicas (Parra, 1985), y que comienzan a ser reconocidos socialmente por jugar un rol hasta entonces desconocido en sus familias y en el conjunto de la sociedad: ser estudiantes primarios, secundarios o de universidad (Duarte, 2005). Decimos diferenciada para relevar que según clase social, género, etnia y localización terri-

4 Comparada con Europa, es muy poca la producción investigativa sobre la situación de las clases de edades menores en nuestro continente para dicho período. Lo que se ha producido suele tener como punto de partida el período colonial o el posterior a las guerras que buscaban independencia en el siglo XIX.

5 O alguna figura de formación de familia con responsabilidades en su materialización. 
torial (urbana o rural), la conflictividad social se expresó en procesos de integración/exclusión a la naciente escuela. Los jóvenes varones de la clase oligarca fueron los que primero accedieron a este proceso, más tarde los varones pobres y las mujeres de la oligarquía y mucho después los sectores femeninos más pobres de las emergentes ciudades y de las poblaciones campesinas (Illanes, 1991).

Este dinámico proceso de emergencia de sectores jóvenes en la sociedad chilena, iniciado aproximadamente a mediados del siglo diecinueve, va a alcanzar un punto máximo de despliegue; es decir, se consolida en las diversas clases sociales, en ambos géneros y sectores territoriales (rurales y urbanos) a fines de la década del sesenta y principios del setenta del siglo pasado. Uno de los factores estructurales que más incide en ello, es la ampliación de la cobertura educacional en el nivel secundario y terciario - con asimetrías de clase, género y localización territorial (Oyarzún, 2000; Bellei, 2000)—, el acceso al mundo del trabajo para los jóvenes de ambos sexos está más abierto con precarias condiciones para los sectores más empobrecidos (Figueroa, 2005) y sobre todo porque surgen en la escena nacional lo que se denominará expresiones culturales juveniles (Zarzuri y Ganter, 2005).

Además de dinámica y diferenciada esta emergencia juvenil y las relaciones entre clases de edad, también es $\sin$ fin. Es decir, se trata de un proceso infinito que aún no concluye y que podemos hipotetizar, seguirá mutando mientras el modo de producción capitalista siga modificando sus ejes de organización. La evidencia que sostiene esta hipótesis es que la educación superior se ha ido ampliando en matrícula y en duración (Meller, 2010) a partir de las demandas que el mercado laboral y de consumo imponen. Esto último ha implicado que el momento de salida de la clase de edad juvenil se ha ido postergando para los sectores con capacidad de acceso a esta modalidad educativa. En ese sentido podemos decir que tienen más tiempo de juventud y que quienes no acceden a esta posibilidad - transformada en privilegio en Chile - conflictúan sus vidas al experimentar marginación de estas modalidades de ascenso social (Zilveti, 2010). ${ }^{6}$

6 Un matiz a esta hipótesis sugiere incorporar a la influencia del sistema educativo, la construcción social de juventudes que se hace desde el mercado, y que a través de imágenes de éxito por medio del consumo opulento, la productividad eficiente, y/o la modernización tecnológica, imponen modelos de identidad a un conjunto de sujetos/as que se hacen jóvenes a través de estos mecanismos que se pretenden de integración social (Moulian, 1997; Duarte, 2009). Este proceso es situado desde la 
Las evidencias históricas muestran que esta emergencia y construcción de juventudes en las sociedades latinoamericanas y caribeñas poseen una cuarta característica: diversos conflictos en torno al desencuentro entre las expectativas de los mundos adultos respecto de las y los jóvenes y de estos en torno a su papel y a las oportunidades sociales. Esta conflictividad ha venido enfrentándose, desde fines del siglo XIX, con tendencias a propiciar la subordinación de los grupos considerados menores, por medio de la gestación de legislaciones y políticas sociales que han buscado su cooptación en tensas relaciones entre los nacientes Estados nacionales y los grupos de jóvenes en cada país (Goicovic, 2000; Salazar y Pinto, 2002).

Debe considerarse que en estos procesos han existido episodios y procesos de oposición y resistencia de los jóvenes, que enfatizan el carácter conflictivo y dinámico de su emergencia. Para Lutte, citando a Giuliano, las bacanales acontecidas en Roma en los primeros siglos son una muestra de una rebelión de sectores de jóvenes y mujeres empobrecidos contra las nacientes formas de dominación social y política (Lutte, 1992). Para el caso de América Latina, Salazar y Pinto muestran cómo en el siglo XIX se desarrolla una forma de rebelión - por ruptura - con las generaciones de jóvenes, que ya mencionamos, que huyen de sus casas para vagar por los campos y resolver su presente de manera espontánea. Así se niegan a aceptar la herencia de subordinación que el peonaje les imponía, evitando repetir lo que a las generaciones anteriores les había ocurrido (Salazar y Pinto, 2002).

En el ámbito político e institucional, esta emergencia y consolidación de las juventudes se ha producido en relación a un Estado que aparece como productor de violencias sociales. ${ }^{7}$ Es decir, las élites dominantes, las del ámbito económico y del político/cultural, lo han fortalecido como un instrumento que se ha reducido en sus tareas de búsqueda del bienestar social y se potencia como inhibidor de cualquier protesta social y al mismo tiempo articula y organiza los mecanismos que generan las condiciones de pobreza y exclusión social. En ese sentido podemos ubicarle como un actor de violencias estructurales e institucionales.

Cotidianamente en nuestras sociedades, a través de leyes, políticas públicas, normas sociales y otra serie de mecanismos de diverso

posguerra en nuestro continente y se vincula con lo que más adelante veremos como la construcción sociocultural de juventudes.

7 Recurro a ideas planteadas en Duarte, 2006. 
tipo y origen, se impone la necesidad de mantener un cierto orden social de acuerdo a las definiciones hechas por quienes administran este Estado. Para ellos, las situaciones de exclusión social y de pobreza constituyen distorsiones que el mercado, en lo económico, ha de corregir y resolver en la competencia entre individuos. Mientras que aquellas situaciones que van más allá de la ley (desde vagar por las calles hasta ejercer delincuencia internacional), por ejemplo, han de ser abordadas por los dispositivos que ese Estado posee para su corrección y eliminación, lo cual pasa necesariamente por reprimir a las personas señaladas como responsables.

De esta manera, hemos de indagar en las diversas manifestaciones de violencias sociales contra jóvenes, que amparadas en el discurso de la legalidad y el Estado de derecho se ejercen con la complacencia de la población, que en vez de cuestionar su uso más bien refuerzan el castigo hacia las poblaciones jóvenes empobrecidas y de capas medias, en tanto se han puesto al margen o han provocado a la norma social, es decir, «eso les pasa por desobedientes» (Duarte, 1996).

Estos Estados han construido un conjunto de mecanismos: leyes, políticas públicas y normas sociales que le permiten a los grupos dominantes inhibir las expresiones de las poblaciones jóvenes que manifiestan rechazo, cuestionamientos o alternativas a estas imposiciones. Desde normas que exigen-ordenan a ciertos hábitos y comportamientos a las y los jóvenes en sus diversos medios de vida, a políticas públicas mayormente remediales que les ven como beneficiarios pasivos y no les consideran como actores protagónicos, hasta legislaciones en que no se les valida su palabra ni sus experiencias y se les cosifica en tanto la edad que tienen, se verifican un conjunto de fórmulas que expresan los diversos tipos de violencias sociales, en que el Estado de derecho aparece como un sistema aleatorio de violencia/orden en el actual contexto de globalización (Hinkelammert, 2005).

Como se observa, la emergencia de juventudes - y también de niñez - en nuestras sociedades ha estado delimitada por una cierta conflictividad social. Las dinámicas económicas y político institucionales, como parte del modo capitalista de producción, se han consolidado sosteniéndose en un estilo de organización que le otorga a las clases de edades adultas la capacidad de controlar a quienes define como menores, y de esa forma logra asegurar cuestiones básicas como herencia, transmisión generacional y reproducción sistémica. Este estilo de organización desde los mundos adultos ha construido un sistema de dominación al que denominamos adultocentrismo (Duarte, 1994). 
En un primer acercamiento, podemos conceptualizar a este adultocentrismo en un plano material, articulado por procesos económicos y político institucionales, como un sistema de dominación que delimita accesos y clausuras a ciertos bienes, a partir de una concepción de tareas de desarrollo que a cada clase de edad le corresponderían, según la definición de sus posiciones en la estructura social, lo que incide en la calidad de sus despliegues como sujetos y sujetas. Es de dominación ya que se asientan las capacidades y posibilidades de decisión y control social, económico y político en quienes desempeñan roles que son definidos como inherentes a la adultez y, en el mismo movimiento, los de quienes desempeñan roles definidos como subordinados: niños, niñas, jóvenes, ancianos y ancianas. Este sistema se dinamiza si consideramos la condición de clase, ya que el acceso privilegiado a bienes refuerza para jóvenes de clase alta la posibilidad de - en contextos adultocéntricos- jugar roles de dominio respecto, por ejemplo, de adultos y adultas de sectores empobrecidos; de forma similar respecto de la condición de género en que varones jóvenes pueden ejercer dominio por dicha atribución patriarcal sobre mujeres adultas.

Así, adultocentrismo es un sistema de dominación que se fortalece en los modos materiales capitalistas de organización social. No es que antes del capitalismo no existiera, sino que como hemos visto en la historia reciente, este modo de producción se sirve de dicho sistema para su reelaboración continua en lo económico y político. Para reproducirse también se han desplegado mecanismos en el plano de lo cultural y simbólico, que los abordamos a continuación.

\section{ADULTOCENTRISMO COMO MATRIZ SOCIOCULTURAL}

Las transformaciones en la familia, la escuela, la política y el empleo, en Europa y en Latinoamérica y el Caribe, se verifican simultáneamente con elaboraciones del ámbito sociocultural. Ya entrado el siglo $\mathrm{XX}$, estas producciones se hacen sistemáticas incidiendo de forma relevante en el tratamiento simbólico sobre las diversas clases de edad. La noción a la base es que las concepciones circulantes sobre estas clases resultan y dan cuenta de polémicas y debates por establecer los sentidos hegemónicos de dichas elaboraciones, lo que muestra una disputa de poder: «la juventud y la vejez no están dadas sino que se construyen socialmente en la lucha entre jóvenes y viejos» (Bourdieu, 1990:164). En este debate, podemos distinguir básicamente dos 
perspectivas: la que plantea que la juventud es un estado natural de la vida humana, y aquella que señala que constituye una construcción social. Ambas hacen parte de lo que denominamos matriz sociocultural.

\section{a) Ser joven y lo juvenil como estado natural del ser humano}

La noción originaria y hegemónica hasta hace unas tres décadas en la región (Alpízar y Bernal, 2003), es la que sostiene que la juventud constituye una etapa de la vida por la que todos los individuos pasamos, dependiendo del comienzo de la pubertad y de los cambios fisiológicos y hormonales asociados a ella. Esta concepción, naturalizadora de lo juvenil, se despliega sobre la base de una concepción biologicista de la vida, en que dicho ámbito, de manera autónoma, resuelve las cuestiones relativas al desarrollo humano - lo cual se matiza con algunas corrientes que incorporan lo psicosocial como relevante-, pero en dependencia de lo denominado biológico (UNICEF, 2002; Peláez y Luengo, 1996).

Desde la psicología, a comienzos del siglo XX en EE.UU., Stanley Hall elabora una visión que - releyendo a Rousseau y las teorías evolucionistas de Lamarck y Darwin - sostiene la idea de que el desarrollo del individuo reproduce el desarrollo de la especie humana (Hall, 1904). Esto le lleva a concebir la adolescencia como un período prehistórico de salvajismo que requiere de la intervención del mundo adulto, en especial del que se encuentra en el sistema educativo, para llevar adelante tareas civilizatorias con este grupo social (citado en Lutte, 1992). Se configuran procesos de desconfianza hacia las y los jóvenes, se despliegan políticas de control y sumisión a las que aportan de manera relevante las ciencias médicas, sociales (Erikson, 1977; Coleman y Husén, 1989; Parsons, 2008) y educativas (Piaget, 1972). Estas contribuyen para que este sistema de dominación se reproduzca, complementando su sustento material con la construcción de un conjunto de imaginarios sociales que le otorgan legitimidad. ${ }^{8}$

8 Asumimos la noción de imaginarios sociales como «figuras interpretativas de nuestro entorno que le otorgan plausibilidad a una determinada interpretación de 'la realidad social', en la medida que dicha interpretación —en sus grandes rasgos- es socialmente compartida» (Baeza, 2008:105; Cristiano, 2009). Para Bourdieu, en tanto, se trata de una «representación ideológica de la división entre jóvenes y viejos» (1990:163164), una estructura de tipo similar a la de sexo o clase, que funcionan poniendo límites para definir un cierto orden, estableciendo pautas de comportamiento y posicionamiento en dicha estructura. En este caso se 
Después de la Segunda Guerra Mundial y hasta nuestros días los distintos medios de comunicación se integran sistemáticamente en esta tarea de producir juventud, y lo hacen reforzando la lógica de subordinación de la misma. La clave central ha estado en mostrar ciertas características que dicho grupo o tiempo de la vida tendría como una esencia-valor, que se consiguen y es posible transar en el mercado y que refieren a: belleza, lozanía, jovialidad, vigor (Feixa, 1998:42), o aparecen tensionadas con aquellas imágenes que le muestran como portadora de problemas que son señalados como inherentes a su estadio de desarrollo, y para lo cual dichas ciencias han aportado ideas disciplinadoras (Foucault, 1990).

Desde el concepto de objetivación, como proceso social de sedimentación de las subjetividades circulantes, podemos asumir la elaboración de esta perspectiva naturalizadora como parte de los procesos de reificación, en tanto se cristalizan estos imaginarios que se han producido culturalmente y que consiguen ser aceptados como naturales o suprahumanos (Berger y Luckmann, 2003), por lo tanto imposibles de cambiar.

Algunas objetivaciones que podemos distinguir en esta perspectiva naturalizadora son: ${ }^{9}$

i) Mecanicismo: que elabora un itinerario de ciclo vital, lineal, ascendente hasta la adultez, momento en que alcanzaría su punto máximo, y decadente hacia la vejez, en etapas sucesivas definidas por rangos de edad, en que se confunden características del ciclo denominado biológico con las expectativas reproductivas y productivas de la sociedad. Esta parcialización de la complejidad social como mecanicismo reflexivo, objetiva desde la funcionalidad de la persona joven en tanto futuro adulto/a, vale decir, futuro responsable y sostenedor de lo que suceda en su sociedad. Esta lógica imperante tiende a volver rígidas las visiones y versiones acerca de la experiencia de juventud, y su existencia en el ciclo vital y en la cotidianeidad de cada grupo social.

acerca más a la noción de Moscovici (1986) sobre representaciones sociales, en el plano de orientación de la percepción, por lo tanto como un mecanismo. Imaginarios sociales implican la elaboración que resulta de la acción de dichos mecanismos, con este último planteamiento de Baeza (2008), trabajo en este texto.

9 Recurro a ideas planteadas en Duarte, 2001. 
El esquema construido para explicar el ciclo de vida humano acaba siendo el ciclo de vida, con un efecto tal que ya no es posible pensar la vida y el crecimiento humano sino es con las imágenes lineales de etapas, ascenso y descenso ya señalados. El esquema se cristaliza, adquiere vida propia y se autonomiza de sus condiciones de producción.

ii) Universalización: que construye una imagen única para definir qué es la juventud: edad determinada, clase media o alta, estudiante secundario o universitario, varón, urbano, heterosexual, blanco y sin discapacidad física. ${ }^{10}$ Esta universalización como homogeneización se objetiva produciendo la idea cristalizada de que «son todos iguales», existe solo una juventud, singular y total al mismo tiempo.

Planteo más bien que si existiera la juventud, ella no poseería carácter universal. Más bien ella constituye un referente conceptual que precisa de contextualización y especificidad desde sus distinciones entre tipos de jóvenes, entre géneros, razas, clases sociales, estilos (contra) culturales, entre otras claves de lectura.

Lo que existe y que ha venido ganando presencia en nuestras sociedades son las juventudes, vale decir, diversas expresiones y significaciones del entramado complejo que surgen desde un grupo social y que se expresan de maneras múltiples y plurales. La juventud niega existencia, porque ella cierra y mecaniza las miradas; rigidiza y vuelve superficial el complejo entramado social que denominamos las juventudes (Duarte, 2001).

iii) Esencialismo: que a partir de la idea mítica de juventud como fuerza y vigor intrínseco, les impone la tarea de ser quienes están llamados a transformar el mundo. Esta idealización de la juventud como objetivación esencialista se sostiene sobre la imagen de que «son los salvadores del mundo» (Kuasñosky y Szulik, 1996). O sea, se endosa a las y los jóvenes una responsabilidad como los portadores de las esperanzas de cambio y de transformación de las distintas esferas de la sociedad, por el solo hecho de ser jóvenes. Su carácter intrínseco sería ser críticos e innovadores.

Esta versión del imaginario se halla muy difundida, incluso entre organizaciones e instituciones sociales que llegan a la objetivación mesiánica de plantear que «todo lo juvenil es bueno». La noción adul-

10 Este proceso de homogeneización ha llevado a la invisibilización, por ejemplo de las mujeres, en la producción de conocimiento, investigación sobre juventud tal como critican Alpízar y Bernal (2003) y Berga (2007). 
tocéntrica de que ser joven es poseer una capacidad natural para activarse por el cambio social ha llevado a una suerte de fascinación con ciertos procesos históricos y a tratar de explicar la participación y el compromiso político juvenil sin considerar las condiciones históricas que hicieron que dicho compromiso surgiera y se materializara.

Ser joven y comprometerse con la transformación social es una opción de vida que no está condicionada por las características del desarrollo hormonal puberal. Ser joven y comprometerse con la transformación social está en directa relación con las experiencias sociohistóricas que cada sujeto experimenta y los aprendizajes que desde ellas pueda elaborar. Así su procedencia, socialización, despliegue cultural, educación, amistades y afectos, opciones laborales y sexuales, sueños, contexto de país, etcétera, incidirán en mayor o menor medida para forjar lo que cada persona va decidiendo ser y hacer en su vida (Duarte, 2003).

iv) Estigmatización: que a partir de nociones de la juventud y sus prácticas como un problema social, la objetiva como conflicto, maldad inherente y riesgo social. Esta estigmatización, que se hace del grupo social juventud y de sus prácticas y discursos, resulta en una objetivación invisibilizadora del tipo «son un problema para la sociedad». Así la relación que las distintas sociedades construyen con sus jóvenes o con su juventud tiende a fundarse básicamente desde los prejuicios (Goffman, 2003). No se logran vínculos humanizadores, sino que se dan mayormente a partir de imágenes elaboradas desde las apariencias y las miradas preconcebidas por otras y otros. Se tiende a patologizar a la juventud, no se reconocen sus capacidades y potencialidades; de este modo se les saca de la historia, se les sitúa como no aporte y como una permanente tensión para el orden, el progreso y la paz social.

Esta forma de imaginar a las y los jóvenes desde los prejuicios negativos $-\mathrm{y}$ como ya vimos en el esencialismo, pueden ser o pretenderse positivos - incide de manera importante en los relatos socioculturales sobre jóvenes y lo juvenil. Por ello es pertinente asumir el carácter conflictivo que hemos señalado sobre la constitución de juventudes en cada sociedad y cultura, así como el necesario debate y deconstrucción a que debe postularse para que dichas construcciones apunten a la humanización tanto de las relaciones (inter e intra) generacionales como de las identidades juveniles (Duarte 2005).

Un aspecto relevante y de carácter global en la construcción de estas objetivaciones es el uso que se ha hecho de la edad como un dato de- 
finidor de realidad. Si bien ha sido necesaria para el análisis demográfico, la tensión aparece cuando se le utiliza como un factor explicativo de estilos de vida, conductas esperadas, (grados de) madurez, (obtención de) identidad, entre otros tópicos: «la edad es un dato biológico socialmente manipulado y manipulable; muestra que el hecho de hablar de los jóvenes como de una unidad social, de un grupo constituido, que posee intereses comunes, y de referir estos intereses a una edad definida biológicamente, constituye en sí una manipulación evidente» (Bourdieu, 1990; 165). Este uso arbitrario y manipulador incide en la reificación de las imágenes producidas en torno a la edad, influyendo tanto en la construcción de juventud (Bourdieu, 1990) como en el análisis social sobre lo juvenil (Ghiardo, 2004; Martín Criado, 1998), desde perspectivas que refuerzan códigos de dominio adultocéntrico.

Para Sagrera, existiría un sistema discriminatorio al que denomina edadismo, que tiene «capacidad de rechazar, marginar, cosificar a casi todas las personas durante casi toda la vida» (1992:12), y que se organiza a partir de los imaginarios construidos en torno a las edades. Los efectos de este sistema serían la negación de la condición de persona humana, la construcción de grupos cerrados como «razas enemigas» y la obstaculización de la solidaridad entre clases de edad.

A partir de estas objetivaciones reificadas, esta perspectiva naturalizadora tiende a ordenar de manera asimétrica las relaciones sociales produciendo imágenes que permiten interpretaciones orientadas establecer dominio y a reproducirlo - y que son compartidas en nuestra sociedad como imaginarios adultocéntricos, ya no solamente respecto de juventudes, sino también de niñez, adultez y vejez.

\section{b) Ser joven y lo juvenil como construcción sociocultural}

La perspectiva de construcción sociocultural de lo juvenil se sostiene en el ejercicio que historiza su emergencia vinculándola a las condiciones contextuales en cada época, y a la noción de conflicto social que ya señalamos; en ese sentido, también se trata de un ejercicio de objetivación (Berger y Luckmann, 2003). Este ejercicio de objetivación historizada tiende a producirse con intentos por tomar distancia de la perspectiva naturalizadora.

El campo de la elaboración de conocimientos sistemáticos sobre lo juvenil, que se desarrolla desde la perspectiva de construcción sociocultural, puede ser caracterizado como constituyendo ciertos enfoques de pensamiento que buscan no producir (ni reproducir) reifica- 
ciones. Para ello establecen criterios de vigilancia epistemológica (Bourdieu y otros, 2008) que, para el caso de lo juvenil son, entre otros, la consideración del dinamismo y de la infinitud en la construcción social de lo juvenil (Duarte, 2005). De esta manera, por lo menos tres enfoques podemos distinguir en esta perspectiva: ${ }^{11}$

i) Construcción social de tipo funcionalista: que define lo juvenil como un proceso cuyas características más significativas están dadas por el contexto social, político, cultural y económico en que se vive el tiempo que, cada sociedad en específico define como juventud. De esta forma, aspectos identitarios como la clase social de pertenencia, el género, el origen racial, la localización territorial, la adscripción (contra) cultural, entre otros, tienen un peso significativo en su conformación de identidad y en la experiencia de joven que se vivencia.

$\mathrm{Si}$ bien este enfoque constituye un avance significativo respecto de la perspectiva naturalizadora, no constituye una garantía de que se logre ir más allá de las miradas adultocéntricas antes señaladas. Se reiteran en algunas producciones las lógicas de poder de dominio contenidas en dicha matriz, que ven a las y los jóvenes como sujetos en espera para ser, cuestión que lograrán al hacerse socialmente adultos, integrándose en las vías institucionales previstas para ello, asumiendo la subordinación y obediencia como condición para dicho proceso (Weinstein, 1994; Sandoval, 2003; CEPAL, 2004).

ii) Construcción social de tipo culturalista: que realiza «un giro hacia la cultura» enfatizando «la construcción de un sujeto juvenil enmarcado por la cultura» (Zarzuri y Ganter, 2005:10) y que concibe lo juvenil a partir de sus producciones culturales propias y las relaciones con las lógicas de poder social (Hall, 1983; Hebdige, 1994), incluidas las tendencias de nueva sociabilidad a partir de procesos de neotribalización (Maffesoli, 1990). Un eje de atención de estos enfoques es la espectacularidad de los estilos juveniles, en la medida en que se convierten en marcas de identidades de los grupos que los despliegan, a los que también se les denomina subculturas, contraculturas o microculturas (Zarzuri y Ganter, 2002).

Algunos aspectos a debatir en este enfoque se relacionan con: a) la preeminencia del signo en sus estudios, que es asumido como uno de los componentes centrales del estilo juvenil, llevando a que en el análisis dichas expresiones se vean totalizadas en sí mismas por ese

11 Recurro a ideas planteadas en Duarte, 2005. 
estilo, lo que debilita muchas de las miradas sobre las prácticas juveniles; ${ }^{12}$ b) la nula y débil vinculación que se hace de esas realidades juveniles estudiadas, con las condiciones de vida de las y los jóvenes en determinados contextos de desarrollo, que redundan en miradas muy acotadas que pierden capacidad comprensiva de relacionarse con lo global y de ver en ello disputas de poder (Zarzuri y Ganter, 2005); c) la utilización mecanicista que se ha hecho de las nociones de neotribalidad y tribus urbanas, que niegan continuidades entre los modos de agrupación juvenil actuales con épocas anteriores y que homogeneizan la misma diversidad a la que apelan tras estas nociones (Maffesoli, 1990).

Hemos de considerar que existe diversidad al interior de este enfoque culturalista, ya que además de lo señalado están marcando un sendero interesante en la observación de las juventudes los trabajos de Feixa (1998) sobre culturas juveniles en México; los aportes de Roxana Reguillo (2000) y Carlos Mario Perea (2007) que incorporan la clave de acción política en las expresividades y producciones (contra) culturales juveniles.

iii) Construcción social desde lo generacional. En continuidad con el enfoque que señala la existencia de una matriz adultocéntrica en nuestras sociedades y que lo juvenil emerge desde una construcción social, se ha venido desplegando una elaboración que propone mirar lo social como constituido también por generaciones (además de clases, género, etcétera), enfatizando en la existencia o ausencia de relaciones entre ellas y en las características de sus conformaciones y de dichas relaciones. ${ }^{13}$

Si bien es incipiente su desarrollo, esta corriente aporta interesantes posibilidades en el debate estudiado, ya que permite: i) comprender lo juvenil como relaciones sociales en permanente construcción (dinámicas, diferenciadas e infinitas); ii) leer generaciones en la historia como construcción permanente: dinámicas, diferenciadas, infinitas.

12 Mario Margulis señala: «Como puede suceder en algunos enfoques culturalistas cuando el aspecto signo invade la totalidad de un fenómeno social, lo fragmenta y, por ende lo empobrece» (1996:5).

13 Es interesante el planteamiento de Enrique Martín Criado que señala que la perspectiva generacional tiene su propio desarrollo desde Ortega y Gasset y Mannheim en la primera parte del siglo XX, pero no ha sido oportunamente retomada por la sociología de la juventud en las décadas posteriores (Martín Criado, 1998). Esta situación ha comenzando a variar en América Latina con las producciones de Margulis, 1996; Ghiardo, 2004; Duarte, 2005; Muñoz, 2009, entre otros. 
Esto es lo que en sociología se llamaría complejidad, pero no en el sentido de lo complicado e inexplicable, sino en perspectiva de movimiento y transformación permanente, de lo multifactorial y de lo históricamente condicionado (Vivanco, 2010); iii) leer lo juvenil como una construcción relacional permanente evitaría lecturas juvenilizadas de lo social; iv) articular lo generacional como matriz de análisis que desnaturaliza conflictos generacionales y que permite historizarlos en cada época y cultura; v) comprender las relaciones de poder existente entre generaciones y al interior de las mismas, tanto en sus variantes de dominación como de liberación; vi) comprender lo juvenil desde los vínculos generacionales con las condiciones de construcción de identidades de género, clase, etnia, adscripción (contra) cultural, localización territorial, etc.; vii) construir nuevas concepciones de adultez y vejez, para que sean concebidas desde lógicas liberadoras no adultocéntricas; viii) relevar la singularidad y diferencia de las generaciones para desde ahí coconstruir procesos de movilización fundados en el respeto a dicha diversidad; ix) orientar para el diseño de estrategias de acción desde los propios mundos juveniles y en estilos de coconstrucción con otros grupos sociales (Duarte, 2005).

Dos indicaciones globales en esta perspectiva de construcción sociocultural. Se hace parte de una polémica, de una disputa por establecer sentidos en el debate sobre juventudes y lo juvenil en nuestras sociedades. En una mirada epistemológica global vemos que los diversos enfoques señalados - en un ejercicio clasificatorio, que como tal es arbitrario y parcial - dan cuenta también de concepciones de sociedad y de cultura distintas que son parte de las que hoy pugnan por establecer ciertas hegemonías de pensamiento social, lo mismo en referencia al enfoque naturalizador antes visto. En segundo término, y a partir de lo anterior, la emergencia de este enfoque y su diversidad de corrientes en él dan cuenta — en el esquema de Kühn (1971) — de la existencia de una cierta anomalía, «en que se ha salido al camino de las conceptualizaciones tradicionales, intentando instalar en la reflexión otros elementos no considerados hasta ahora para mirar, aprehender y comprender a las juventudes en nuestras sociedades» (Duarte, 2001:28).

A partir de ambos enfoques, y en un segundo acercamiento conceptual, significamos a este adultocentrismo en un plano simbólico, verificado en procesos del orden sociocultural, como un imaginario social que impone una noción de lo adulto - o de la adultez- como punto de referencia para niños, niñas y jóvenes, en función del deber 
ser, de lo que ha de hacerse y lograr, para ser considerado en la sociedad, según unas esencias definidas en el ciclo vital. Este imaginario adultocéntrico constituye una matriz sociocultural que ordena - naturalizando - lo adulto como lo potente, valioso y con capacidad de decisión y control sobre los demás, situando en el mismo movimiento en condición de inferioridad y subordinación a la niñez, juventud y vejez. A los primeros se les concibe como en 'preparación hacia' el momento máximo y a los últimos se les construye como 'saliendo de'. De igual manera, este imaginario que invisibiliza los posibles aportes de quienes subordina, re visibiliza pero desde unas esencias (que se pretenden) positivas, cristalizando nociones de fortaleza, futuro y cambio para niñez y juventudes.

Como señala Feixa, la adultez, desde Platón y Aristóteles, se ampara en «el elogio al intermedio justo», referido al varón de mediana edad, que es quien ejerce poder de dominación en la sociedad (Feixa, 1998:29), reafirmándose la vinculación antes abordada entre patriarcado y adultocentrismo.

\section{ACOTACIÓN FINAL}

Por ahora, al intentar redondear esta reflexión, es necesario plantear una cautela analítica: el adultocentrismo como matriz sociocultural no implica contar con una clave que «explica todo», y que por su sola referencialidad otorgará respuestas totales para diversas situaciones sociales; más bien se trata de un sistema de relaciones económicas y político institucionales y de un imaginario de dominación de las sociedades capitalistas y patriarcales, que al ser develados como tales aportan en la mejor comprensión de las dinámicas sociales. Para ello requiere de contextualización y consideración de algunas especificidades sociales en su utilización, tal que mantenga un rendimiento que permita identificar las expresiones manifiestas y latentes de este dominio, así como aquellas posibilidades de transformación.

Otra cautela analítica refiere a que este adultocentrismo, como sensibilidad dominante y violenta, es internalizado como subjetividad y opera como una suerte de identificación inercial en quienes observamos como víctimas de este imaginario: niñas, niños y jóvenes. Estos/as llevan el adultocentrismo dentro de sí, lo reproducen tanto en sus relaciones con las personas mayores en edad, como con quienes son considerados menores que ellos. 
Hasta aquí hemos pretendido aportar elementos comprensivos de la condición adultocéntrica de nuestra sociedad: su emergencia y reproducción. El paso que queda pendiente, en la necesaria deconstrucción analítica, es bosquejar pistas que permitan observar y sistematizar posibilidades de alternativas a los procesos de dominación adultocéntrica:

A partir de las ideas presentadas es posible afirmar que en contextos de sociedad adultocéntrica:

i) Como tendencia, las relaciones entre grupos de edad se han planteado como relaciones de tensión y conflictos;

ii) Esas tensiones y conflictos han sido resueltos desde los mundos adultos, por medio del empleo de fuerza física, cuerpos legales, normativas, políticas públicas y discursos autorreferidos como científicos, en un proceso acumulativo de mecanismos que profundizan en las condiciones de dominación;

iii) Dicha conflictividad varía y se actualiza, muta y se renueva, de acuerdo a las transformaciones que en cada época las sociedades y culturas han adquirido, así como de acuerdo a los diversos roles que los sujetos sociales desarrollan;

iv) Dicha conflictividad se produce desde los mundos adultos por la búsqueda de ocupar posiciones de control y prestigio — poder de dominación - en la estructura social, en las relaciones cotidianas, al decidir lo que otros y otras han de hacer, pensar y sentir, sometiéndolos a ello si es necesario;

v) Dicha conflictividad emergió a partir de aspectos materiales de estas relaciones sociales y posiciones (herencia, acceso a bienes y servicios, liderazgos comunitarios y sociales), y en la contemporaneidad, ella se ha complementado con aspectos de orden simbólico y subjetivo (prestigios, normas, identidades).

vi) La emergencia y consolidación del adultocentrismo como parte del patriarcado ha permitido la concentración de posiciones de poder de dominio en varones adultos.

vii) La emergencia de las y los sujetos jóvenes en las sociedades capitalistas ha sido dinámica, diferenciada infinita y conflictiva, lo que nos habla de diversidades y tensiones en su constitución.

SANTIAGO (CHILE), ABRIL 2012

RECIBIDO, ABRIL 2012

ACEPTADO, MAYO 2012 


\section{REFERENCIAS BIBLIOGRÁFICAS}

Abaunza, Humberto; Irela SolóRzano y Raquel Fernández (1995): Una causa para rebeldes: identidad y condición juvenil en Nicaragua. Managua: Puntos de Encuentro.

AGUILERA, ÓSCAR (2009): «Los estudios sobre juventud en Chile: coordenadas para un estado del arte». Última Década $\mathrm{N}^{\circ} 31$. Valparaíso: Ediciones CIDPA.

ALPÍZAR, LIDIA y MARINA BERNAL (2005): «La construcción social de las juventudes». Última Década $\mathrm{N}^{\circ} 19$. Valparaíso: Ediciones CIDPA.

ARIÉS, PHILLIPE (1990): El niño y la vida familiar en el antiguo régimen. Madrid: Taurus.

BAeza, MANuel ANTONio (2008): Mundo real, mundo imaginario social. Teoría y práctica de la sociología profunda. Santiago: RIL Editores.

BELLEI, CRISTIÁN (2000): «Educación media y juventud en los 90. Actualizando la vieja promesa». Última Década $\mathrm{N}^{\circ} 12$. Valparaíso: Ediciones CIDPA.

BERGA, ANNA (2007): «Adolescencia femenina i risc social». Col-lecció Aportacions $\mathrm{N}^{\circ} 30$. Barcelona: Obsevatori Catalá de la joventut.

BERGER, PETER y THOMAS LUCKMANN (2003): La construcción social de la realidad. Buenos Aires: Amorrortu.

BOURDIEU, PIERRE (1990): La juventud no es más que una palabra. Sociología y cultura. México: Grijalbo.

Bourdieu, PIERRE et al. (2008): El oficio del sociólogo. Presupuestos epistemológicos. Buenos Aires: Siglo XXI.

CARRASCO, PEDRO (1979): «La jerarquía civicorreligiosa en las comunidades de Mesoamérica: antecedentes precolombinos y desarrollo colonial». En LlOBERA (editor): Antropología política. Barcelona: Anagrama.

CEPAL y OIJ (2004): La juventud en Iberoamérica. Tendencias y urgencias. Santiago: CEPAL.

COLEMAN, JAMES y TORSTEN HUSÉN (1989): Inserción de los jóvenes en una sociedad en cambio. Madrid: Narcea.

CRISTIANO, JAVIER (2009): Lo social como institución imaginaria. Castoriadis y la teoría sociológica. Villa María: Eduvim.

DÁVILA, ÓsCAR (2004): «Adolescencia y juventud. De las nociones a los abordajes». Última Década $\mathrm{N}^{\circ} 21$. Valparaíso: Ediciones CIDPA.

DE BEAuvoIR, SIMONE (1998): El segundo sexo. Madrid: Cátedra.

DEMAUSE, LlOYD (1982): Historia de la infancia. España: Alianza Editorial.

DuARTE, Claudio (2009): «Sobre los que no son, aunque sean. Éxito como exclusión de jóvenes empobrecidos en contextos capitalistas». Última Década $\mathrm{N}^{\circ} 30$. Valparaíso: Ediciones CIDPA. (2006): «Violencias en jóvenes, como expresión de las violencias sociales. Intuiciones para la práctica política con investigación social». Revista PASOS $\mathrm{N}^{\circ} 120$. San José de Costa Rica: Departamento Ecuménico de Investigaciones. 
- (2005): «Trayectorias en la construcción de una sociología de lo juvenil en Chile». Persona y Sociedad. Santiago: Universidad Alberto Hurtado. (2003): «Jóvenes entre la maldad y la pureza. A propósito de los treinta años del golpe militar contra el pueblo chileno». Revista ERIAL $\mathrm{N}^{\circ} 10$. Lo Espejo: Programa Caleta Sur.

(1996): «Ejes juveniles de lectura, para desenmascarar las bestias y anunciar los sueños». Revista PASOS Especial N6. San José de Costa Rica: Departamento Ecuménico de Investigaciones.

(1994): Juventud popular. El rollo entre ser lo que queremos o ser lo que nos imponen. Santiago: Lom Ediciones.

— y DANAHÉ ZAMBRANO INTRIAGO (2004): «¿Juventud o juventudes?». En: Acerca de jóvenes, contraculturas y sociedad adultocéntrica. San José de Costa Rica: Departamento Ecuménico de Investigaciones.

ERIKSON, ERIK (1977): Identidad, juventud y crisis. Buenos Aires: Paidós.

FEIXA, CARLES (2001): «Generació@. La joventut al segle XXI». Col-lecció Aportacions $\mathrm{N}^{\circ} 12$. Barcelona: Obsevatori Catalá de la joventut.

— (1998): De jóvenes, bandas y tribus. Antropología de la juventud. Barcelona: Ariel.

FiguerOA, RoDrigo (2003): Desempleo y precariedad en la sociedad de mercado. Santiago: Universidad de Chile, PREDES-RIL.

FOUCAULT, MICHAEL (1990): Vigilar y castigar. Madrid: Siglo XXI.

Gallardo, HeliO (2006): Siglo XXI producir un mundo. San José de Costa Rica: Editorial Arlequín.

GHIARDO, FELIPE (2004): «Generaciones y juventud: una relectura desde Mannheim y Ortega y Gasset». Última Década ํ⒛ Valparaíso: Ediciones CIDPA.

GofFMAN, IRVING (2003): Estigma. La identidad deteriorada. Buenos Aires: Amorrortu ( $10^{\mathrm{a}}$ reimpresión).

GoICOVIC, IGOR (2000): «Del control social a la política social. La conflictiva relación entre los jóvenes populares y el Estado en la historia de Chile». Última Década $\mathrm{N}^{\circ} 12$. Valparaíso: Ediciones CIDPA.

Hall, Stanley (1904): Adolescence. Its Psychology and Its Relations to Physiology, Anthropology, Sociology, Sex, Crime, Religion and Education. New York: Appleton \& Company.

HALL, STUART (1984): «Notas sobre la deconstrucción de lo popular». En R. SAMUEL (editor): Historia popular y teoría socialista. Barcelona: Crítica.

HALL, STUART y TONY JEFFERSON (coordinadores) (1983): Resistance Trough Rituals. Londres: Hutchinson.

HebDige, Dick (1994): Subculture, The meaning of Style. Londres y New York: Routledge.

HINKELAMMERT, FRANZ (2005): «La transformación del estado de derecho bajo el impacto de la estrategia de globalización». Revistas PASOS $\mathrm{N}^{\circ} 117$. San José de Costa Rica: Departamento Ecuménico de Investigaciones. 
(1998): Sacrificios humanos y sociedad occidental. San José de Costa Rica: Departamento Ecuménico de Investigaciones.

(1991): La fe de Abraham y el Edipo occidental. San José de Costa Rica: Departamento Ecuménico de Investigaciones.

Illanes, MARÍA ANGÉliCA (1991): 'Ausente señorita'. El niño chileno, la escuela para pobres y el auxilio. Chile, 1890-1990. Santiago: JUNAEB.

KUASÑOSKY, S. y D. SZULIK (1996): «Desde los márgenes de la juventud». En MARIO MARGULIS (editor): La juventud es más que una palabra. Ensayos sobre cultura y juventud. Buenos Aires: Biblos.

KüHN, THOMAS (1971): La estructura de las revoluciones científicas. México: Fondo de Cultura Económica.

LUTTE, GÉRARD (1992): Liberar la adolescencia. La psicología de los jóvenes de hoy. Barcelona: Herber.

MAFFESOLI, MiCHEL (1990): El tiempo de las tribus. El ocaso del individualismo en las sociedades posmodernas. Barcelona: Icaria Editorial.

MARGULIS, MARIO (editor) (1996): La juventud es más que una palabra. Ensayos sobre cultura y juventud. Buenos Aires: Biblos.

MARTÍN CRIADO, ENRIQUE (1998): Producir la juventud. Madrid: Istmo.

Mead, Margaret (1973): Adolescencia y cultura en Samoa. Buenos Aires: Paidós.

MELlER, PATRICIO (2010): Carreras universitarias: rentabilidad, selectividad y discriminación. Santiago: Uqbar Editores.

Moscovici, Serge (1986): Psicología social II. Pensamientos y vida social. Psicología social y problemas sociales. Buenos Aires: Paidós.

Moulian, Tomás (1997): Chile actual. Anatomía de un mito. Santiago: Lom Ediciones.

MUÑOZ, VÍCTOR (2009): Generaciones. Juventud universitaria e izquierdas políticas en Chile y México (Universidad de Chile-UNAM 1984-2006). Santiago: Mimeo.

OYARZÚN, ÁSTRID (2000): «La cultura juvenil se ha hecho secundaria, pero aún es una allegada». Última Década $\mathrm{N}^{\circ} 12$. Valparaíso: Ediciones CIDPA.

PARRA, RoDRIGO (1985): Ausencia de futuro: la juventud colombiana. Bogotá: CEPAL/Plaza \& Janés.

PARSON, TALCOTT (2008): «La edad y el sexo en la estructura social de Estados Unidos». En VV.AA.: Teorías sobre la juventud. La mirada de los clásicos. México: UNAM.

Peláez, Paula y Ximena Luengo (1996): El adolescente en conflicto. Salud integral. Santiago: Editorial Andrés Bello.

Perea, Carlos Mario (2007): Con el diablo adentro. Pandillas, tiempo paralelo y poder. México: Siglo XXI.

PÉREZ ISLAS, JOSÉ ANTONIO (2006): «Trazos para un mapa de la investigación sobre juventud en América Latina». Papers №79. Barcelona: Universidad Autónoma de Barcelona. 
PiAget, JEAn (1972): De la lógica del niño a la lógica del adolescente. Buenos Aires: Paidós.

POLLOCK, LINDA (1990): Los niños olvidados: relaciones entre padres e hijos de 1500 a 1900. México: Fondo de Cultura Económica.

REGUILlO, RosSANA (2000): Emergencia de culturas juveniles. Estrategias del desencanto. Buenos Aires: Norma.

RODRÍGUEZ, PABLO (2007): «Los hijos del sol: un acercamiento a la infancia en la América Prehispánica». En PABLO RODRÍGUEZ y MARÍA EMMA MANNARELli (coordinadores): Historia de la infancia en América Latina. Bogotá: Universidad Externado de Colombia.

ROJAS, JORGE (1996): Los niños cristaleros: trabajo infantil de la industria. Chile, 1880-1950. Santiago: DIBAM.

SAGRERA, MARTÍN (1992): El edadismo: contra 'jóvenes' y 'viejos', la discriminación universal. Madrid: Fundamentos.

SAlAZAR, GABRIEL y JULIO PINTO (2002): Historia contemporánea de Chile. Niñez y juventud. Tomo V. Santiago: Lom Ediciones.

SANDOVAL, MARIO (2003): Jóvenes del siglo XXI. Sujetos y actores en una sociedad en cambio. Santiago: Universidad Católica Silva Henríquez.

STONE, LAWRENCE (1986): El pasado y el presente. México: Fondo de Cultura Económica.

TuRnBull, Colin (1984): Elima, la danza de la vida. Los pigmeos, el pueblo de la selva. Barcelona: Javier Vergara.

UNICEF (2002): Adolescencia: una etapa fundamental. New York: UNICEF.

Vivanco, MANuEL (2010): Sociedad y complejidad del discurso al modelo. Santiago: Universidad de Chile y Lom Ediciones.

WeInSteIn, José (1994): «Los jóvenes y la educación media». Primer informe nacional de juventud. Santiago: Instituto Nacional de la Juventud.

ZARZURI, RAÚl y RODRIGO GANTER (compiladores) (2005): «Jóvenes: la diferencia como consigna. Ensayos sobre la diversidad cultural juvenil. Santiago: CESC.

$-\mathrm{y}-$ (2002): Culturas juveniles, narrativas minoritarias y estéticas del descontento. Santiago: Universidad Católica Silva Henríquez.

ZILVETI, MAYA (2010): «Cultura del empleo accesorio: dimensiones socioculturales implicadas en la no-inserción laboral juvenil». Tesis para optar al grado de Magíster en Antropología Social. Santiago: Universidad de Chile. 